\title{
Functional outcomes after combined iris and intraocular lens implantation in various iris and lens defects
}

\author{
Christian S. Mayer ${ }^{1,2}$, Andrea M. Hoffmann², Phillipp Prahs ${ }^{3}$, Lukas Reznicek ${ }^{2}$ and Ramin Khoramnia ${ }^{{ }^{*}}$ (D)
}

\begin{abstract}
Background: To assess the functional outcomes after combined iris and intraocular lens (IOL) repair in aniridia patients.

Methods: Retrospective observational study in 59 aniridic and aphakic eyes for Artificiallris (AI) and IOL reconstruction. The iris prostheses were placed together with the $\mathrm{IOL}$ in the capsular bag using an injection system or were fixed by transscleral suturing of the IOL and Al. The primary outcomes measured were visual acuity, contrast and glare sensitivity (Pelli-Robson chart for photopic and dark adaptometer for mesopic conditions), intraocular pressure, endothelial cell density (ECD) and patient impairment.

Results: Blunt trauma (37 eyes) and penetrating injuries (16 eyes) were observed more frequently than congenital aniridia (1 eye), iatrogenic causes (1 eye), aniridic state after severe iritis (2 eyes) or iris tumor (2 eyes). Monocular CDVA improved significantly $(p<0.0001)$ from median $0.7 \log$ MAR $(0.0-1.98)$ to $0.3 \log M A R(-0.08-2.0)$. Median pupillary area could significantly $\left(p<0.0001\right.$ ) be reduced by $79.3 \%$ from $51.27 \mathrm{~mm}^{2}$ (17.91 to 98.23 ) to $8.81 \mathrm{~mm}^{2}$ (4.16 to 8.84). Median ECD decreased from $2646.0 \mathrm{~mm}^{2}$ to $2497.5 \mathrm{~mm}^{2}$ ( $p=0.007$ ). Contrast and glare sensitivity improved significantly $(p=0.008)$ in photopic light conditions from $0.9(0.0-1.95)$ to $1.35(0.0-1.8)$. Patients reported to be highly satisfied with the functional improvement.
\end{abstract}

Conclusion: The flexible Artificiallris seems to be a safe and effective iris prosthesis in combination with an IOL having functionally and cosmetically exceptional reconstruction options.

Keywords: Aniridia, Pupillary reconstruction, Ocular trauma, Eye injury, IOL

\section{Background}

Iris defects either from congenital, traumatic or other causes come in various dimensions and may lead to considerable visual impairment. Photophobia, increased glare from bright light, decreased visual acuity and contrast sensitivity are the most common symptoms in aniridic patients. These patients may also suffer extensively from

\footnotetext{
* Correspondence: Ramin.Khoramnia@med.uni-heidelberg.de

'Department of Ophthalmology, University Hospital Heidelberg, University of Heidelberg, Im Neuenheimer Feld 400, 69120 Heidelberg, Germany

Full list of author information is available at the end of the article
}

the unaesthetic appearance of their eyes, particularly in case of substantial iris loss.

The management of congenital aniridia can be very challenging because of the complexity of the disease and the association with severe ocular comorbidities [1]. More often, iris abnormalities result from traumatic injury, e.g. blunt trauma or penetrating eye injuries. Posttraumatic eyes may also present morphological and functional alterations due to ocular injuries, for example corneal damage and lens lesion [2]. In respect of the high rate of secondary impairment, careful management

(c) The Author(s). 2020 Open Access This article is licensed under a Creative Commons Attribution 4.0 International License, which permits use, sharing, adaptation, distribution and reproduction in any medium or format, as long as you give appropriate credit to the original author(s) and the source, provide a link to the Creative Commons licence, and indicate if changes were made. The images or other third party material in this article are included in the article's Creative Commons licence, unless indicated otherwise in a credit line to the material. If material is not included in the article's Creative Commons licence and your intended use is not permitted by statutory regulation or exceeds the permitted use, you will need to obtain permission directly from the copyright holder. To view a copy of this licence, visit http://creativecommons.org/licenses/by/4.0/ The Creative Commons Public Domain Dedication waiver (http://creativecommons.org/publicdomain/zero/1.0/) applies to the data made available in this article, unless otherwise stated in a credit line to the data. 
is needed to improve the patients' quality of vision and cosmetic appearance.

Conservative therapeutic approaches for aniridia include iris print contact lenses, corneal tattooing, sunglasses, occlusion intraocular lenses and simple iris suturing for small defects of approximately 2 clock hours. However, in case of large iris defects, implantation of a prosthetic iris device may be more appropriate.

Currently, several models are available, including the foldable custom-made CUSTOMFLEX ARTIFICIALIRIS from HumanOptics (Erlangen, Germany). The device received the CE marking in 2011 and is the only iris prosthesis that received FDA approval (2018) for the treatment of vision and cosmetic problems arising from congenital, surgical or traumatic aniridia in adults and children.

It is available with or without embedded polymer fiber meshwork and can be implanted through small corneal incisions within the capsular bag or ciliary sulcus with or without scleral fixation. The various implantation techniques of the artificial iris for the management of complete or partial aniridia have been extensively described elsewhere [3]. The favorable outcomes in terms of functional vision, aesthetics and patient satisfaction have also been largely reported in the literature [4-9]. Nonetheless, complications may occur, but as shown in our previously published work, the complication rate decreases indirectly proportional to the increasing experience and the learning curve of the surgeon [10].

In this retrospective study, we focused on the functional rehabilitation after implantation of the artificial iris in 59 eyes with large aniridic defects and simultaneous need for intraocular lens (IOL) implantation due to cataract or aphakia. We therefore evaluated the subjective patients' impairment in terms of glare, contrast sensitivity under photopic and mesopic conditions and the subjective impairment with a questionnaire pre- and postoperatively.

\section{Methods}

This retrospective observational case series comprised 59 eyes of 56 patients who were implanted with the CUSTOMFLEX $X^{\circ}$ ARTIFICIALIRIS and an intraocular lens in one session over a period of 7 years (2011/092018/04). Patients were referred to the clinic for ocular trauma in 53 eyes $(89.83 \%)$, iris tumor in 2 eyes $(3.39 \%)$, aniridic state after severe iritis in 2 eyes (3.39\%), congenital aniridia in one eye $(1.69 \%)$ and iatrogenic aniridia in one eye $(1.69 \%)$.

Prior to surgery, details of the surgical procedure were explained to all patients and written and verbal informed consent was obtained from all participants. The study was conducted according to the tenets of the Declaration of Helsinki, and approval by the Institutional Review Board was obtained.

To evaluate the severity of ocular injuries, we initially classified the eyes based on the Ocular Trauma Score (OTS) according to Kuhn et al. [11]. The OTS evaluating system is calculated by assigning numerical raw points to six variables: initial visual acuity, rupture of the globe, penetrating injury, endophthalmitis, retinal detachment, and afferent pupillary defect. The score is then stratified into five categories ( 1 to 5 ): the higher the score the less the traumatic level.

\section{Surgical management}

All surgeries were performed by one surgeon (CM) in general anesthesia. The preparation of the artificial iris and the different implantation procedures have been previously described in detail [3]. In brief, before implantation of the artificial iris, phakic patients underwent either standard cataract surgery with IOL implantation in the capsular bag or an IOL was sutured to the sclera in cases where no capsular bag was available. Patients received either a one-piece hydrophilic acrylic IOL (ASPI RA-aAY, HumanOptics AG, Erlangen, Germany) in the capsular bag $(n=15)$ respectively sutured to the $\mathrm{AI}(n=$ 30) (Fig. 1) or a PMMA IOL for scleral fixation $(n=14)$ (Type 81B, Morcher GmbH, Stuttgart, Germany) when they had inadequate capsule or zonula support or were primarily aphakic.

Artificial iris implants were placed through an approx. $7.0 \mathrm{~mm}$ superior sclerocorneal incision into the ciliary sulcus and then sutured. In 15 eyes, however, the IOL and artificial iris were placed in the capsular bag. For a more detailed description we can refer to a previous publication [3]. We generally choose the artificial iris version with embedded fiber in cases of suturing the iris prosthesis; otherwise the fiber free version was implanted. If suturing

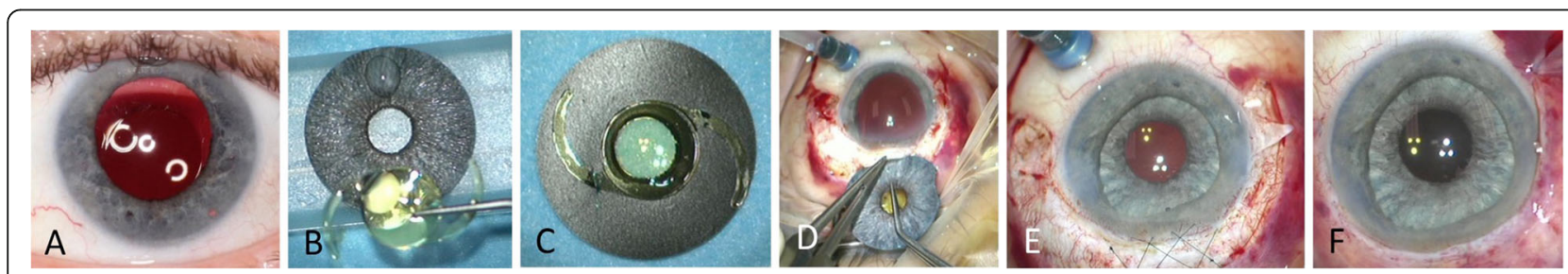

Fig. 1 From preoperative state (a), combined preparation of the Al and IOL (b and $\mathbf{c}$ ), implantation of the "sandwich" through a sclerocorneal incision (c) and suturing to the sclera (e) to postoperative outcome $(\mathbf{f})$ 
was not necessary, the prosthesis was injected through a $2.8 \mathrm{~mm}$-sized superior corneal incision using a shooter system (Viscoject 2.2, Medicel AG, Thal, Switzerland). Surgeries lasted between 20 and 125 min (median 74.0 $\min ; 71.69 \pm 31.14 \mathrm{~min}$ ).

\section{Study parameters}

All patients were examined preoperatively and followed-up at least 3 months after surgery. A comprehensive ophthalmic examination including biomicroscopic evaluation of the anterior and posterior eye segment, Goldmann applanation tonometry and the measurement of intraocular pressure (IOP) were performed at all visits.

Study parameters assessed preoperatively and at the 5 months follow-up were the following: corrected distance visual acuity (CDVA); photopic and mesopic contrast sensitivity (CS); endothelial cell density (ECD), pupil area and patient's satisfaction in terms of changes in symptoms of light sensitivity and daytime glare results.

All visual tests were performed monocularly. Distance visual acuity was measured using standardized optotypes at $5 \mathrm{~m}$ distance. Contrast sensitivity under photopic and mesopic conditions was measured with best correction using the Pelli-Robson chart (test distance of $1 \mathrm{~m}$ ). Furthermore, an evaluation of the sensitivity to glare was performed with the Nyktometer 500 (test disc 505, Rodenstock GmbH, Munich, Germany). The Nyktometer test disc 505 consists of 12 Landolt rings with four different contrast levels. Time for pre-adaptation to mesopic light conditions was at least $3 \mathrm{~min}$ for each patient. Both tests were performed with glare (Pelli-Robson chart; Nyktometer $0.3 \mathrm{~cd} / \mathrm{m}^{2}$ ).

The ECD, pupil area and postoperative pupillary shift under photopic illuminations were measured with the Konan Specular Microscope NSP-9900 (medtec GmbH, Mömbris, Germany). To analyze the amount of reduction of the pupil area and the centration of the iris prosthesis postoperatively, digital images of the eye were taken using the HEYEX (Heidelberg Eye Explorer, Heidelberg Engineering $\mathrm{GmbH}$, Germany). The area of pupillary aperture was calculated in pixels and converted into square millimeters for analysis. The maximum distance between the pupil center and the corneal center was considered as the pupillary shift.

For the evaluation of patient impairment, patients were asked to rate their glare sensitivity on a visual ana$\log$ scale ranging from 1 to $10(1=$ none, $10=$ maximum disturbance) before and after iris reconstruction.

\section{Data analysis}

We used Analyse-it ${ }^{\bullet}$ for Microsoft ${ }^{\bullet}$ Excel 5.11 for all statistical analyses. Decimal visual acuities and contrast sensitivity scores were converted into logMAR and logarithmic units, respectively. Hence, adjusted meter visions such as counting fingers (CF), hand motion (HM), and light perception (LP) were defined as $1.9(\mathrm{CF}), 2.0(\mathrm{HM})$ and 2.1 (LP) logMAR.

The non-parametric Wilcoxon test for paired samples was used to compare CDVA, IOP, CS, SE, ECD, pupil area, and patient impairment results. All tests were twotailed, and significance level was set at a $p$-value of 0.05 .

\section{Results}

In total, 59 eyes of 56 patients were evaluated in this retrospective observational study, comprising 43 male $(76.79 \%)$ and 13 female subjects (23.21\%). Median age was 56.5 years (range, 28.0 to 84.0 years). Figure 2 shows the percentage of preoperatively recorded types and severities of trauma, respectively. Median CDVA prior to surgery was $0.70 \log$ MAR (range 0.00 to $1.98 \operatorname{logMAR}$ ). Median period of time between the diagnosis and the surgery was 37.0 months (range, 1.0 to 79.2 months). Prior to the implantation, 56 iris prostheses were

\section{A Defect type}

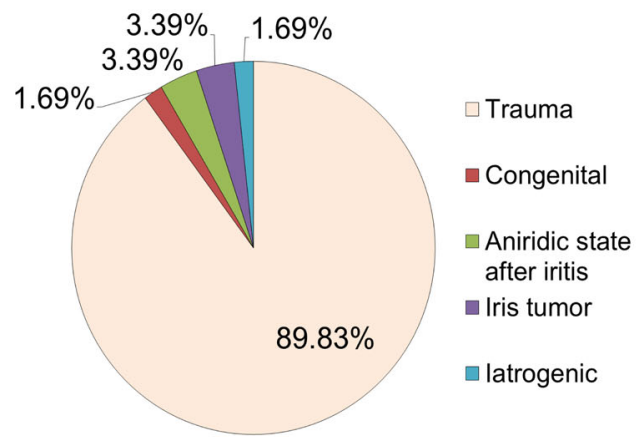

B OTS Score

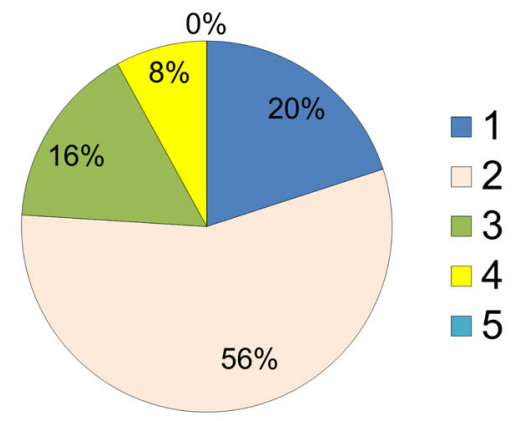

Fig. 2 a Percentage of defect types $(n=59)$. b OTS scores from 1 to 5 (the higher the score, the less trauma; eyes without previous trauma were excluded; $n=50$ ) underline the fact that many of the treated eyes were severely pre-damaged 
downsized to a smaller diameter (median, $11.50 \mathrm{~mm}$; range, 9.0 to $12.50 \mathrm{~mm}$ ).

Monocular CDVA at 5 months was significantly better than preoperatively $(p<0.0001) .54 \%(32 / 59)$ of patients had an improvement of $0.2 \log$ MAR or greater, $34 \%(20 / 59)$ had an improvement of less than 0.2 logMAR and $12 \%(7 / 59)$ lost $0.2 \operatorname{logMAR}$ or more. $75 \%$ of eyes achieved a CDVA better than or equal to 0.7 logMAR. There were no significant changes in IOP values $(p=0.881)$. Photopic and mesopic contrast sensitivity could only be recorded in 36 and 28 eyes, respectively. Logarithmic contrast sensitivity scores under photopic conditions with glare improved significantly from preoperative to postoperative measurements $(p=0.008)$. Under mesopic light conditions with glare, no significant differences were found $(p=0.844)$. Table 1 summarizes the preoperative and postoperative findings.

\section{Pupil area and endothelial cell density}

Median pupil area was significantly reduced from 51.27 $\mathrm{mm}^{2}$ (17.91 to 98.23 ) to $8.81 \mathrm{~mm}^{2}$ (4.16 to 8.84 ) postoperatively $(p<0.0001)$, representing a median reduction of $79.30 \%$. There was a median pupillary shift of the iris prostheses amounting to $0.28 \mathrm{~mm}$ (0.02 to 1.04) from the center of the cornea.

Median ECD also decreased slightly but significantly $(p=0.007)$ from $2646.0 \mathrm{~mm}^{2}$ (737.0 to 3145.0 ) to 2497.5 $\mathrm{mm}^{2}$ (728.0 to 3067.0).

\section{Adverse events and complication management}

No adverse events occurred during the surgery procedure. Postoperatively, six eyes $(10 \%)$ presented complications due to device dislocation (one needed re-fixation by sutures) in four cases and development of glaucoma in two cases which was controlled with conservative

Table 1 IOP, CDVA, contrast sensitivity levels (log) and sensitivity to glare

\begin{tabular}{llll}
\hline & Preoperatively & Postoperatively & $p$-value \\
\hline IOP (mmHg) & & & \\
Median (range) & $15.0(8.0$ to 30.0$)$ & $15.0(9.0$ to 27.0$)$ & 0.881 \\
Mean \pm SD & $15.2 \pm 4.0$ & $15.0 \pm 3.8$ & \\
CDVA (logMAR) & & & \\
Median (range) & $0.70(0.0$ to 1.98) & $0.30(-0.08$ to 2.00$)$ & $<0.0001$ \\
Mean \pm SD & $0.84 \pm 0.61$ & $0.55 \pm 0.61$ & \\
Contrast sensitivity & & & 0.008 \\
(Pelli-Robson chart) & & $1.35(0.00$ to 1.80$)$ & \\
Median (range) & $0.90(0.00$ to 1.95$)$ & $1.26 \pm 0.40$ & 0.844 \\
Mean \pm SD & $0.96 \pm 0.55$ & & \\
Nyktometer 500 & & $0.00(0.00$ to 23.5) & \\
Median (range) & $0.00(0.0$ to 23.5) & $2.11 \pm 6.12$ & \\
Mean \pm SD & $2.07 \pm 6.15$ & &
\end{tabular}

medication. Secondary surgery was immediately performed to suture the subluxated iris prostheses resulting in stable and safe positioning. In addition, one eye developed chronic irritation paired with persistent macular edema and corneal decompensation; hence, the artificial iris was explanted after 16 months.

\section{Questionnaire}

Patients were asked to rate subjectively their complaints before and after surgery. Glare was rated from 1 (no glare) to 10 (extreme glare). Preoperatively, median glare score was 9.0 (range 1 to 10 ; mean $7.9 \pm 2.9$ ) and was significantly reduced after surgery to a median score of 4.0 (range 1 to 10 ; mean $3.9 \pm 2.4)(p<0.0001)$.

\section{Discussion}

If iris prostheses are needed, the eyes are oftentimes severely pre-damaged. Eye injuries in association with iris trauma usually affect other parts of the eye, especially the cornea. This can potentially lead to a loss of vision. In retrospective analyses of patients with major trauma or blunt injuries, study results $[2,12]$ revealed that the incidence of iris deficiency was $0.5 \%$ up to $20.0 \%$ including iris sphincter tears and iridodialysis. Insertion of iris prostheses in traumatic eyes should be performed in such a way that an additional trauma is reduced to a minimum (e.g. sclerocorneal incision in eyes with compromised corneas of small corneal incisions in eyes with weak scleral tissue). Without the need of placing fixation sutures, the foldable CUSTOMFLEX ARTIFICIALIRIS can be implanted in the posterior chamber using an IOL injector [13].

In our study comprising 59 eyes, penetrating injuries and blunt trauma were the most common mode of injury representing $89.8 \%$ of the eyes. Some subjects had undergone preceding surgeries such as pars plana vitrectomy, which sometimes had taken place several years before implantation of the artificial iris.

Due to the surgical procedure, the median visual acuity initially decreased 2 days after surgery, and then continuously rose at later follow-up visits; however, the initial decrease did not show any significance compared to preoperative measurements. The postoperative visual acuity however, improved significantly. At the follow-up, visual acuity improved in 41 eyes (73\%) and remained stable in 2 eyes (4\%) but worsened in 13 eyes (23\%). Factors for limited increase of postoperative visual outcomes were central corneal scarring and clouding, dislocation of the ArtificialIris, and persistent macular edema. Regarding corneal opacities, Ayliffe et al. [13] claimed that efforts should be made to place the prosthetic pupil in alignment with the clearest, centrally located area of the cornea. However, this could lead to aesthetic dissatisfaction on closer eye inspection. In our study though, patients were subjectively 
rather affected by glare. More precisely, it primarily seems to be more important to abate the patients' sensitivity to glare using an appropriate artificial aperture (Fig. 3). However, we also showed in a recent study that aniridia treatment using a custom-made AI prosthesis offers a good aesthetic outcome [14]. Pre- and postoperative photographs of 66 patients were analyzed subjectively and objectively. Patients, eye doctors and laymen rated the overall aesthetic outcome with $8.9 \pm 1.4,7.7 \pm 1.1$ and $7.3 \pm 1.1$ out of 10 points, respectively [14].

As already reported in detail [15-17], haptic fixation of a foldable IOL on the back of the Artificiallris provides advantages regarding sutureless and knotless transscleral fixation. Although remaining foldable, the scleral-fixated IOL-iris complex cannot be inserted using an injector. Nonetheless, the ArtificialIris generally offers the possibility to simultaneously correct aphakia or cataract in aniridia when required, which substantially improves vision. A previous laboratory assessment also showed that suturing of the IOL to the AI can be done in a reliable and reproducible manner without deteriorating optical quality [18].

Compared to normal controls, visual performance of injured eyes appears to be worse in terms of low contrast conditions [19]. Since glare effects and pupil size deviations are crucial factors for the reduction of contrast sensitivity [20], the results in our patients were below the age-related standard contrast sensitivity values in normal persons [21, 22] because of significant traumatic iris tissue loss. In general, postoperative contrast sensitivity improved at photopic and mesopic luminance levels, although this tendency was not statistically significant in mesopic conditions but in photopic. As the overall pupil size of the ArtificialIris amounts to $3.35 \mathrm{~mm}$ providing improved contrast sensitivity levels at daytime light conditions, it had to be clarified whether the fixed pupil diameter might be less well adapted to mesopic luminance levels. The results obtained, however, suggest that the predefined size of the pupil does not negatively affect mesopic vision under glare influence.

It is generally known that severe complications after introducing prosthetic iris devices can be as follows: secondary glaucoma, persistent inflammation, retinal detachment, and corneal problems [23-27]. Therefore, proper placement and fixation of the implant is required to avoid mechanical contact between the Artificiallris and either the lens or the corneal endothelium. According to Gerding et al. [23], insufficient stabilization of the iris prosthesis can cause secondary glaucoma and complete endothelial cell loss with the consequence of penetrating keratoplasty. As expected, low median ECD amounting to less than 2000 cells $/ \mathrm{mm}^{2}$ was found in 11 eyes before surgical invasion, which fell by an average of 8.41\% after implantation of the ArtificialIris. Compared with results in healthy eyes [28], mean endothelial cell loss was within the normal range, although we found a sharp decrease of more than $30 \%$ in three eyes. The variable and sometimes great loss of endothelial cells is most likely caused by the time-demanding and rather invasive procedure required. To protect the corneal endothelium in these oftentimes severely pre-damaged eyes, we recommend the extensive use of ophthalmic viscosurgical

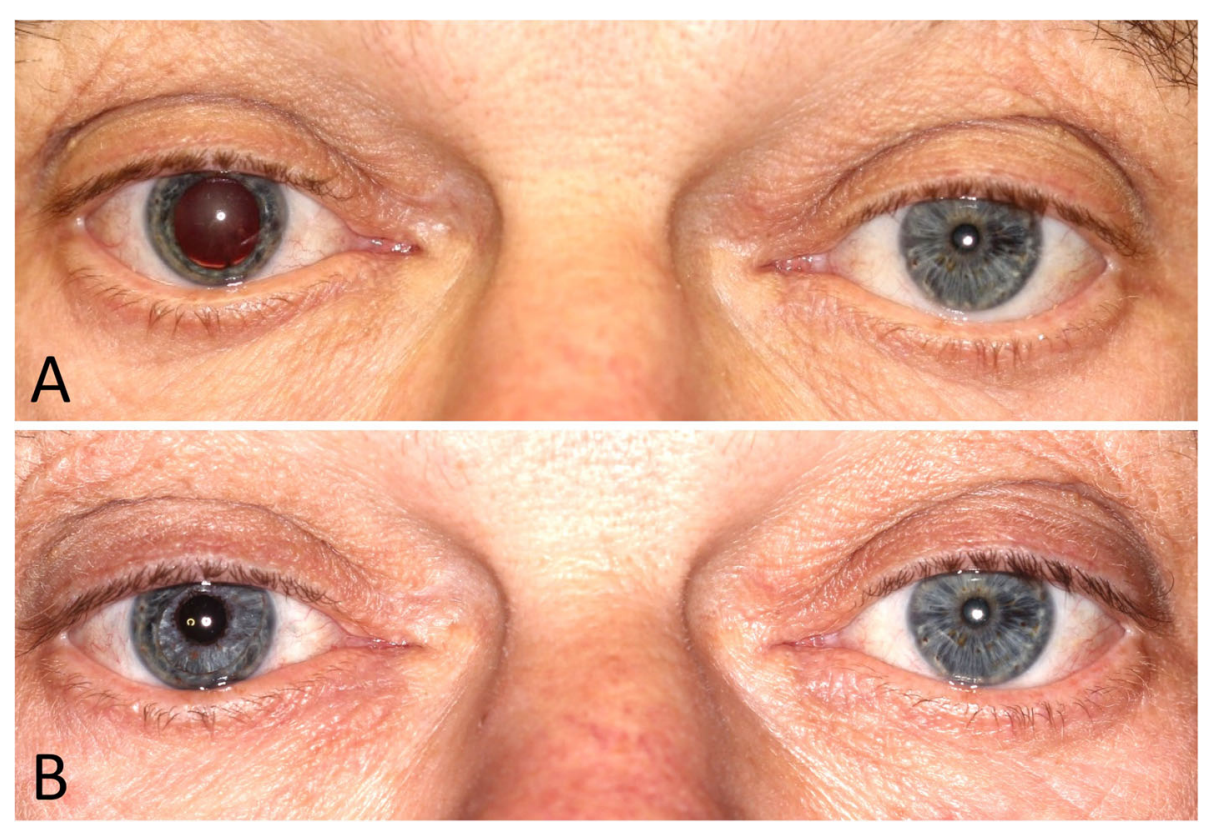

Fig. 3 Patient before and after combined artificial iris and IOL implantation (right eye; same patient as in Fig. 1) 
devices (OVD). As mentioned earlier, when suturing of the iris prostheses was not indicated we used a $2.8 \mathrm{~mm}$ incision. We used an approx. $7.0 \mathrm{~mm}$ wide sclerocorneal incision to implant the devices when suturing was indicated. We did not notice any differences in rate of complications due to the larger incision, however, we agree with the literature that large incisions should be avoided in eyes with previous trauma [13]. This is particularly necessary to minimize unnecessary additional corneal trauma. In our study cohort, one eye developed secondary corneal decompensation followed by explantation of the ArtificialIris.

After repair of the initial ocular trauma and before ArtificialIris implantation, some of the patients wore commercially available iris print contact lenses to conceal their iris deficiencies, but with partly limited success due to translucent printing, incompatibility reaction, and poor compliance. Despite having intraocular intervention, we therefore assume that the ArtificialIris offers better results regarding handling, cosmetic [9] and functional rehabilitation on a continuing basis and reduces risk for contact lens induced complications to the cornea. Moreover, this prosthetic iris device has proven to be convenient in ocular comorbidities $[5,8,13]$.

\section{Conclusion}

To sum up, the implantation of an ArtificialIris in combination with an individual IOL can be a life-enhancing procedure. Glare disability is significantly decreased, severe photophobia is eliminated and refractive disorders are corrected. The described approach offers an additional option to surgeons to treat partial or total aniridia as well as aphakia in one single surgery. Finally, our observational case series confirmed the findings of previous reports showing very few severe adverse events regarding ArtificialIris implantation, if cautious handling and application is warranted.

\section{Abbreviations}

CDVA: Corrected distance visual acuity; CE: European certification mark; CF: Counting fingers; CS: Contrast sensitivity; ECD: Endothelial cell density; FDA: U.S. Food and Drug Administration; HM: Hand motion; IOL: Intraocular lens; IOP: Intraocular pressure; logMAR: logarithm of the Minimum Angle of Resolution; LP: Light perception; OTS: Ocular trauma score; PMMA: Poly (methyl-methacrylate)

\section{Acknowledgments}

Not Applicable.

\section{Authors' contributions}

CSM conceived and supervised the study and performed all surgeries. CSM, $\mathrm{AMH}, \mathrm{PP}, \mathrm{LR}$ and RK contributed to the collection and analysis of the data. CSM wrote the initial manuscript, revised by RK. All authors critically reviewed the paper for important intellectual content and approved the final version to be published.

\section{Funding}

We acknowledge financial support by Deutsche Forschungsgemeinschaft within the funding programme Open Access Publishing by the Baden-
Württemberg Ministry of Science, Research and the Arts and by RuprechtKarls-Universität Heidelberg. Open access funding provided by Projekt DEAL.

Availability of data and materials

The data used to support the findings of this study are available from the corresponding author upon request.

\section{Ethics approval and consent to participate}

Ethics committee approval by the Technische Universität München, Fakulät für Medizin, Ethikkommission, Ismaninger Str. 22, 81675 München, Germany. Written and verbal informed consent was obtained from all participants.

\section{Consent for publication}

Written and verbal informed consent was obtained from all participants.

\section{Competing interests}

The authors do not have any competing interests.

\section{Author details}

'Department of Ophthalmology, University Hospital Heidelberg, University of Heidelberg, Im Neuenheimer Feld 400, 69120 Heidelberg, Germany. 2Department of Ophthalmology, University Hospital Klinikum rechts der Isar, Technical University of Munich, Munich, Germany. ${ }^{3}$ Department of Ophthalmology, University of Regensburg, Regensburg, Germany.

Received: 2 March 2020 Accepted: 20 August 2020

Published online: 15 September 2020

\section{References}

1. Chang JW, Kim JH, Kim S-J, Yu YS. Congenital aniridia: long-term clinical course, visual outcome, and prognostic factors. Korean J Ophthalmol. 2014; 28(6):479-85.

2. Viestenz A, Kuchle M. Retrospective analysis of 417 cases of contusion and rupture of the globe with frequent avoidable causes of trauma: the Erlangen Ocular Contusion-Registry (EOCR) 1985-1995. Klin Monatsbl Augenheilkd. 2001;218(10):662-9.

3. Mayer C, Tandogan T, Hoffmann AE, Khoramnia R. Artificial iris implantation in various iris defects and lens conditions. J Cataract Refract Surg. 2017; 43(6):724-31.

4. Koch KR, Heindl LM, Cursiefen C, Koch HR. Artificial iris devices: benefits, limitations, and management of complications. J Cataract Refract Surg. 2014;40(3):376-82.

5. Rosenthal KJ, Venkateswaran N. Clinical and ultrasound biomicroscopic findings in a patient with anterior vaulting of a customized, flexible artificial iris. J Refract Surg. 2013;29(10):663-4.

6. Rana M, Savant V, Prydal Jl. A new customized artificial iris diaphragm for treatment of traumatic aniridia. Cont Lens Anterior Eye. 2013;36(2):93-4.

7. Magnus J, Trau R, Mathysen DG, Tassignon MJ. Safety of an artificial iris in a phakic eye. J Cataract Refract Surg. 2012;38(6):1097-100.

8. Budo C. Iris repair after long-term complications of agle-supported phakic intraocular lenses. Open J Ophthalmol. 2012;2:40-3.

9. Mayer CS, Reznicek L, Hoffmann AE. Pupillary reconstruction and outcome after artificial iris implantation. Ophthalmology. 2016;123(5):1011-8.

10. Mayer CS, Laubichler AE, Khoramnia R, Tandogan T, Prahs P, Zapp D, Reznicek L. Challenges and complication Management in Novel Artificial Iris Implantation. J Ophthalmol. 2018;2018:3262068.

11. Kuhn F, Maisiak R, Mann L, Mester V, Morris R, Witherspoon CD. The ocular trauma score (OTS). Ophthalmol Clin N Am. 2002:15(2):163-5 vi.

12. Guly CM, Guly HR, Bouamra O, Gray RH, Lecky FE. Ocular injuries in patients with major trauma. Emerg Med J. 2006:23(12):915-7.

13. Ayliffe W, Groth SL, Sponsel WE. Small-incision insertion of artificial iris prostheses. J Cataract Refract Surg. 2012;38(2):362-7.

14. Yildirim TM, Khoramnia R, Masyk M, Son H, Auffarth GU, Mayer CS Aesthetics of iris reconstruction with a custom-made artificial iris prosthesis. PLoS One. 2020;15(8):e0237616. https://doi.org/10.1371/journal.pone. 0237616. eCollection 2020

15. Spitzer MS, Yoeruek E, Leitritz MA, Szurman P, Bartz-Schmidt KU. A new technique for treating posttraumatic aniridia with aphakia: first results of haptic fixation of a foldable intraocular lens on a foldable and customtailored iris prosthesis. Arch Ophthalmol. 2012;130(6):771-5. 
16. Gooi P, Teichman JC, Ahmed II. Sutureless intrascleral fixation of a customtailored iris prosthesis with an intraocular lens. J Cataract Refract Surg. 2014; 40(11):1759-63.

17. Forlini C, Forlini M, Rejdak R, Prokopiuk A, Levkina O, Bratu A, Rossini P, Cagampang PR 3rd, Cavallini GM. Simultaneous correction of post-traumatic aphakia and aniridia with the use of artificial iris and IOL implantation. Graefe's Arch Clin Exp Ophthalmol. 2013;251(3):667-75.

18. Mayer C, Son HS, Łabuz G, Yildirim TM, Auffarth GU, Khoramnia R. In vitro optical quality assessment of a monofocal intraocular lens sutured to an artificial iris. J Cataract Refract Surg. 2020;46(8):1184-8.

19. Coe CD, Bower KS, Brooks DB, Stutzman RD, Hammer JB. Effect of blast trauma and corneal foreign bodies on visual performance. Optom Vis Sci. 2010;87(8):604-11.

20. Arranz I, Matesanz B, Issolio L, Menéndez J, Mar S, Aparicio J. Light adaptation in letter contrast sensitivity: the influence of optical and neural mechanisms. Lighting Res Technol. 2014;46(4):476-88.

21. Puell MC, Palomo C, Sanchez-Ramos C, Villena C. Normal values for photopic and mesopic letter contrast sensitivity. J Refract Surg. 2004; 20(5):484-8.

22. Mantyjarvi M, Laitinen T. Normal values for the Pelli-Robson contrast sensitivity test. J Cataract Refract Surg. 2001;27(2):261-6.

23. Gerding H, Hailemariam S, Timmermann M. Complications after prosthetic iris implantation in a case of traumatic aniridia. Klin Monatsbl Augenheilkd. 2013;230(4):323-5.

24. Burk SE, Da Mata AP, Snyder ME, Cionni RJ, Cohen JS, Osher RH. Prosthetic iris implantation for congenital, traumatic, or functional iris deficiencies. J Cataract Refract Surg. 2001;27(11):1732-40

25. Mashor RS, Bahar I, Kaiserman I, Berg AL, Slomovic A, Rootman DS. Combined penetrating keratoplasty and implantation of iris prosthesis intraocular lenses after ocular trauma. J Cataract Refract Surg. 2011; 37(3):582-7.

26. Taneri $\mathrm{S}$, Gerding H. Retinal detachment and phthisis bulbi after implantation of an iris prosthetic system. J Cataract Refract Surg. 2003; 29(5):1034-8.

27. Mayer CS, Laubichler AE, Masyk M, Prahs P, Zapp D, Khoramnia R. Residual Iris retraction syndrome after artificial Iris implantation. Am J Ophthalmol. 2019:199:159-66.

28. Sanchis-Gimeno JA, Lleo-Perez A, Alonso L, Rahhal MS, Martinez Soriano F. Corneal endothelial cell density decreases with age in emmetropic eyes. Histol Histopathol. 2005;20(2):423-7.

\section{Publisher's Note}

Springer Nature remains neutral with regard to jurisdictional claims in published maps and institutional affiliations.

Ready to submit your research? Choose BMC and benefit from:

- fast, convenient online submission

- thorough peer review by experienced researchers in your field

- rapid publication on acceptance

- support for research data, including large and complex data types

- gold Open Access which fosters wider collaboration and increased citations

- maximum visibility for your research: over $100 \mathrm{M}$ website views per year

At BMC, research is always in progress.

Learn more biomedcentral.com/submissions 